\title{
Management of Intra Operative Over- Reduction of Traumatic AAD with Fracture of C1-C2 Vertebrae: Case Report \& Review of Literature
}

\author{
Rashim Kataria ${ }^{1}$, Mudit Mehrotra ${ }^{2 *}$, Devendra K Purohit ${ }^{1}$ and Nachiket Dharker ${ }^{3}$ \\ ${ }^{1}$ Department of Neurosurgery, SMS Medical College, India \\ ${ }^{2} S M S$ Medical college, India \\ ${ }^{3}$ Senior Bioinformatics Analyst, USA
}

Submission: January 27, 2021; Published: March 17, 2021

*Corresponding author: Mudit Mehrotra, SMS Medical College, India

\section{Abstract}

Intra operative reduction of dislocated C1-C2 joints involves joint manipulation and varying degrees of distraction, compression and extension components. This holds good in cases of congenital Atlanto-axial dislocation (AAD) with Basilar invagination (BI). In cases of traumatic $\mathrm{AAD}$ associated with fracture of C1-C2 vertebrae, the joints may be hypermobile and grossly unstable because of the injured osseous-ligamentous complex. Distraction in these cases can cause traction on the brain stem or cervical cord, as well as over reduction of the C1-C2 joints leading to spinal canal compromise. We report a case of traumatic AAD (translation / rotatory/ lateral tilt) with fractures of C1-C2 vertebrae. While performing intra operative reduction, there was over reduction of C1-C2 joints. The management and available literature is discussed.

Keywords: Traumatic; Atlanto-axial dislocation; Distraction; Over reduction; C1-C2 vertebrae

Abbreviations: BI: Basilar Invagination; MJOA: Modified Japanese Orthopaedic Association Score; AAD: Atlanto Axial Dislocation; CT: Computed Tomography; DCER: Distraction Compression Extension Reduction; MRI: Magnetic Resonance Imaging; ADI: Atlanto Dental Interval; PADI: Posterior Atlanto Dental Interval

\section{Introduction}

The most common dislocation of the $\mathrm{C} 1-\mathrm{C} 2$ facet in cases of traumatic AAD is horizontal where-in $\mathrm{C} 1$ slides anterior relative to $\mathrm{C} 2$ [1]. Usually gentle joint manipulation, compression and extension reduces the dislocation pre-operatively. On the other hand, distraction and flexion further worsen the dislocation. There is a scope for distraction in cases of $\mathrm{BI}$, which is associated with most of the congenital AADs, however, a distraction in traumatic $\mathrm{AAD}$ (without $\mathrm{BI}$ ) can cause traction on the brainstem or cervical cord and may lead to a neurological deficit in the patient. There is not enough literature available on how exactly the reduction should be attempted in a particular case and what are the salvage procedures when there is an overcorrection of the reduction which is refractory to any compression or distraction manoeuver of C1-C2 joints. Here we discuss one such case where we faced an over correction of C1-C2 joint dislocation causing intraoperative hypotension and bradycardia with reduced effective spinal canal diameter.

\section{Case Report}

A 23-year-old man presented with a history of road traffic accident 7 days prior to the surgery with chief complaints of neck pain and weakness in all four limbs. The patient was conscious, alert, with power $3 / 5$ in the right shoulder and elbow joint and $4 / 5$ in the rest of the muscle groups, the grip was reduced to $20 \%$ in right hand and was $100 \%$ in the left hand. The modified JOA score was $14 / 18$. MRI of the cervical region revealed a fracture of the dens of the $\mathrm{C} 2$ vertebra with posterior displacement of the $\mathrm{C} 2$ vertebral body with its lateral deviation. This resulted in canal stenosis and cord compression at the cervico-medullary junction with cord edema (Figure 1A). The patient underwent a CT scan of CV junction, which revealed a fracture at the base of the odontoid process with anterolisthesis of $\mathrm{C} 1$ over $\mathrm{C} 2$ causing cord compression (Figure 2). CT angiography showed normal bilateral vertebral arteries and jugular veins. The 3D printed model [2] was also the same as the patient which gave us some additional 
information and revealed a lateral tilt of the $\mathrm{C} 1$ vertebral body towards the left side (Figure 1B). In addition, the patient had an undisplaced C1 anterior arch fracture. The AAD was translational with rotatory and lateral tilt.

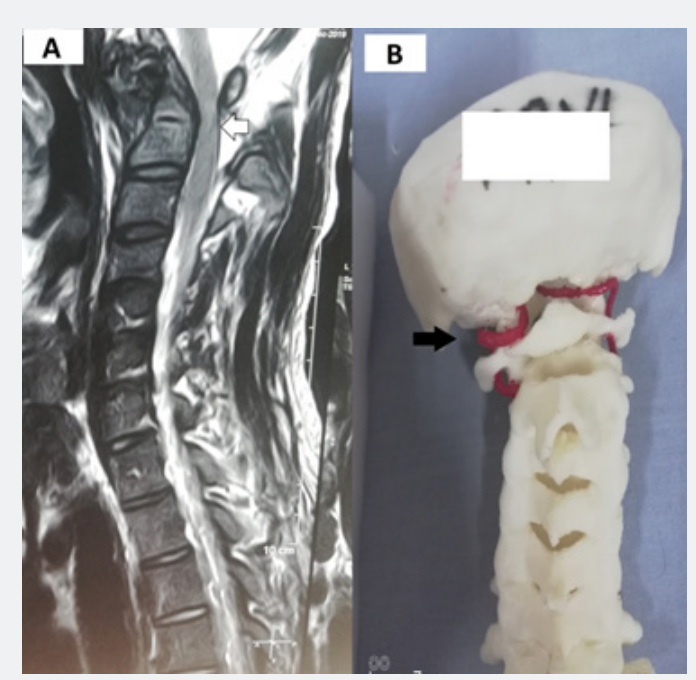

Figure 1: A) MRI scan saggital section showing $A A D$ with decreased effective canal diameter due to retropulsed odontoid (C2) (solid white arrow), B) 3D model of the patient showing lateral tilt (solid black arrow).

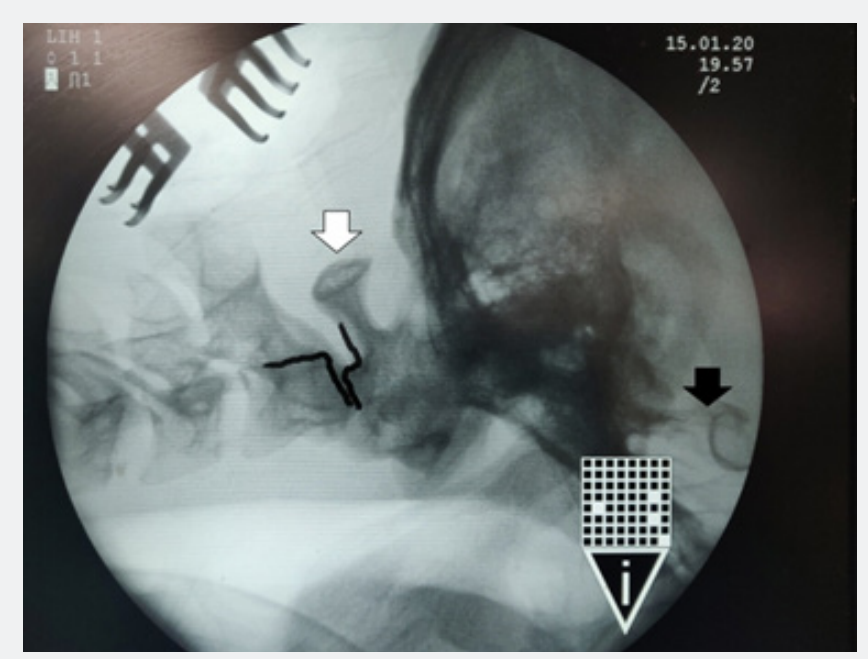

Figure 2: Showing anterolisthesis of $\mathrm{C} 1$ over $\mathrm{C} 2$ causing cord compression taken through $\mathrm{C}$-arm (solid white arrow). The $\mathrm{C} 1$ lateral mass shadows and posterior spinal line at the level of $\mathrm{C} 2$ is made dark intentionally.

\section{Management}

The patient underwent emergency surgery as he developed urinary incontinence. The intubation was done with minimal neck manipulation using fiber optic laryngoscopy. Following general anaesthesia the patient was placed in the prone position on a horse-shoe headrest with adequate padding to avoid ocular injury and Crutchfield skull traction was applied to stabilize the cervical spine and to distract the fractured segment [3]. Traction weight of about $16 \mathrm{~kg}$ was used [4]. In our case the patient presented with weakness in all 4 limbs as a result of traumatic AAD. A standard midline skin incision was given. The occiput, posterior edge of foramen magnum, upper cervical spine was exposed. The patient was operated using the posterior approach and we tried to correct the AAD using distraction, joint manipulation with C1-C2 fixation (Figure 3) [5]. The slight distraction of C1-C2 joints was performed using a small vertebral body distractor and a chisel. Small autologous iliac bone grafts were inserted in C1-C2 joints on both sides. Bilateral $\mathrm{C} 1$ lateral mass screws and $\mathrm{C} 2$ pedicle mass screws were inserted, rods applied, and nuts tightened, which led to overcorrection and abnormal posterior overtranslation of $\mathrm{C} 1$ over C2. This could be well appreciated intraoperatively as the $\mathrm{C} 1$ posterior arch, which was anterior at the beginning of surgery, got shifted posteriorly, and was almost in level with the spinous process of $\mathrm{C} 2$ vertebra, leading to Cord compression as 
evident on C-arm and shown in (Figure 4). As a result, the patient developed hypotension with bradycardia intraoperatively. The rods were made loose from the tulips of the screws, and the over reduction persisted even after applying compression or extension over C1 \& C2 tulips as well as on manual pushing of C1 posterior arch anteriorly. It did not improve even after the removal of skull traction or the intra-articular bone grafts. Following this, the C1 screws in the bilateral C1 lateral mass were removed (Figure 5).
The patient had improvement in hemodynamic parameters after the removal of rods connecting C1-C2 screws. The Occiput-C2 construct was performed instead, as this was the most optimal option available at that time. A satisfactory reduction was achieved during this procedure as seen in (Figure 6). Autologous bone graft was laid over the posterior surface of C1- C2 joints after making their posterior surface raw with a cutting burr.

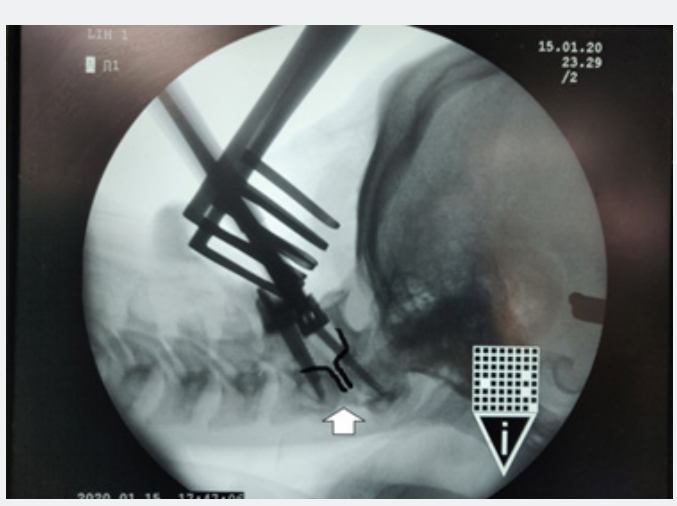

Figure 3: C-arm image showing C1 lateral mass screws and C2 pedicle screws (solid white arrow) with some reduction of the AAD. The borders of $\mathrm{C} 1-\mathrm{C} 2$ vertebrae have been darkened.

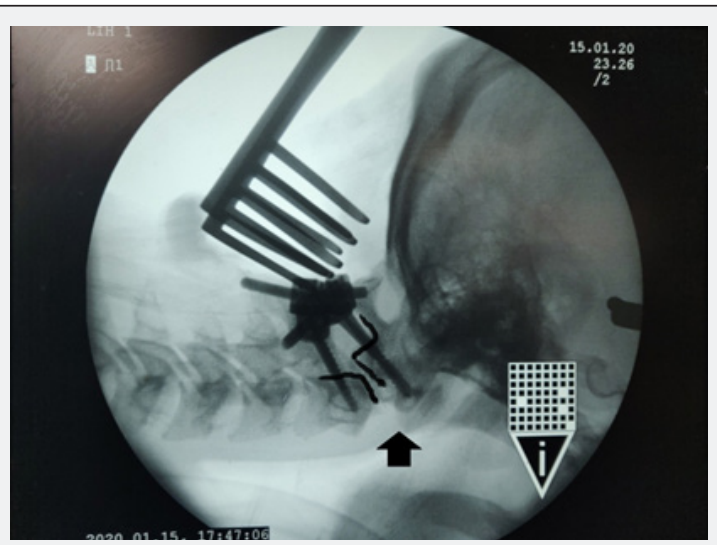

Figure 4: C-arm image showing overcorrection and posterior translation of $\mathrm{C} 1$ over $\mathrm{C} 2$ leading to decreased effective canal diameter following distraction (solid black arrow). The borders of C1-C2 vertebrae have been darkened.

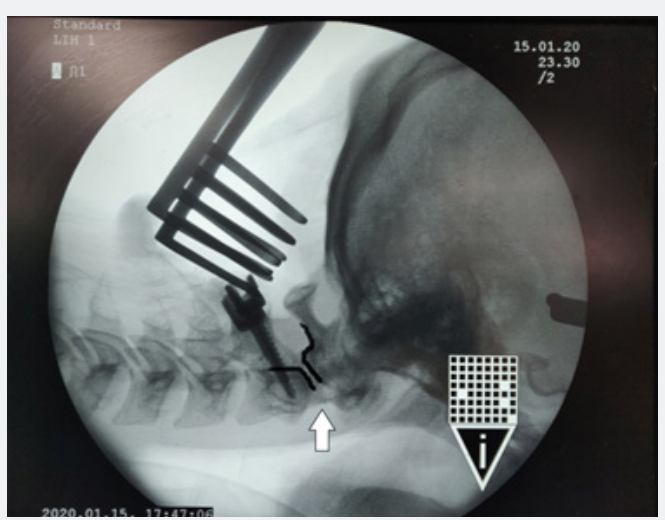

Figure 5: Attempts were made to manually push the $\mathrm{C} 2$ anteriorly following posterior over translation of $\mathrm{C} 1$ over $\mathrm{C} 2$ which led to Cord compression, but no improvement was seen, hence $\mathrm{C} 1$ screws in bilateral C1 lateral mass were removed. C-arm image after removal of C1 screws showing partial improvement in effective canal diameter (solid white arrows). The borders of C1-C2 vertebrae have been darkened. 


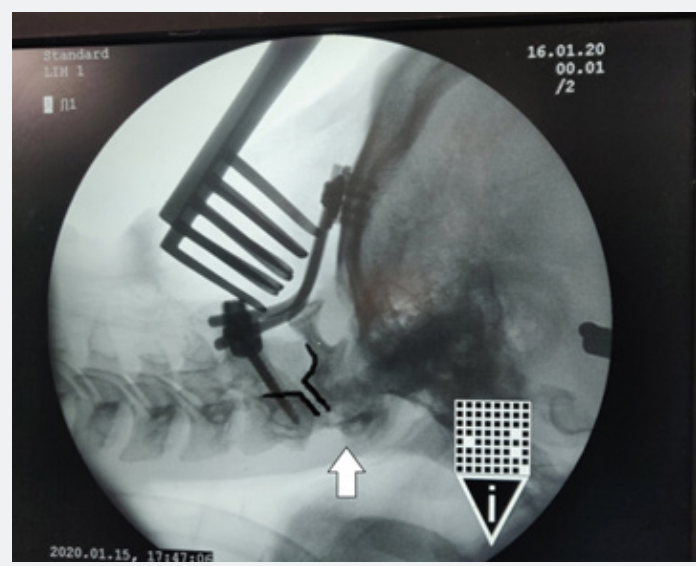

Figure 6: $\mathrm{C}$-arm image showing Occiput-C2 construct with satisfactory reduction at C1-C2 level (solid white arrow). The borders of C1-C2 vertebrae have been darkened.

\section{Outcome}

The patient improved significantly immediately after the surgery with $4 / 5$ power in the right upper limb and grip increased to $50 \%$ in the right hand, power $5 / 5$ in rest of the limbs and modified JOA (mJOA) score improved to 16/18. At 3 months follow up the patent had mJOA score of $16 / 18$ with power $4 / 5$ in the right upper limb and power $5 / 5$ in rest of the limbs. One year follow up of the patient shows well aligned CV junction with power $5 / 5$ in all 4 limbs.

\section{Discussion}

The traumatic atlanto-axial subluxation can be divided into 3 possible types [6]. In Type A there is a forward subluxation of $\mathrm{C} 1$ over $\mathrm{C} 2$ causing an increase in the ADI with a reduction of the PADI. There is no substantial increase in the C1-C2 interspinous distance. These constitute the classical post traumatic AAD. Type B comprises of forward subluxation of C1 over C2 associated with an odontoid fracture and an intact transverse ligament. In this case, the ADI is not increased. Our patient had a Type B atlantoaxial subluxation. Lastly in Type $\mathrm{C}$ the $\mathrm{C} 2$ moves posteriorly and superiorly in the sagittal plane and the $\mathrm{C} 1$ arch goes downward and forward causing an increase in the ADI and increase in the C1-C2 interspinous distance, both of which may be increased on flexion. In type A and B subluxations, the reduction is achieved by applying traction on the $\mathrm{C} 1$ arch in a posterior direction and pressure is applied on $\mathrm{C} 2$ spinous process in an anterior and upward direction. The reduction is achieved after which a fixation and fusion procedure is performed [6]. In cases with type C subluxation, a modified reduction procedure is performed. In these cases, the interspinous ligaments between C1-C2 and the muscles attached to the $\mathrm{C} 2$-C3 posterior elements are dissected to allow movement at $\mathrm{C} 2-\mathrm{C} 3$ interspinous region after which the $\mathrm{C} 1$ arch is manipulated in the downward and backward direction. Simultaneously, a vertebral distractor is placed between C2-C3 laminae and the interspinous space distracted under fluoroscopy till reduction is attained, following which fixation of $\mathrm{C} 1-\mathrm{C} 2$ is performed [6]. C1-C2 joint dissection and joint manipulation is a well established technique for the reduction of traumatic/ congenital AAD [6]. Distraction component of joint manipulation is well tolerated in cases of $\mathrm{BI}$, but in cases of traumatic AAD without $\mathrm{BI}$, distraction can have devastating outcomes as was seen in this case $[7,8]$. Traction also forms the mainstays of patients with $\mathrm{CV}$ junction injuries either to achieve a reduction or for immobilisation. Now-a-days cervical traction is either applied a day before the surgery or after induction of anesthesia. The weights applied for traction are approximately $5 \mathrm{~kg}$ or onesixth of the total body weight. The patient is placed prone with the head end of the table elevated to about 35 degrees. Cervical traction stabilizes the head in an optimally reduced extension position and prevents any rotation. Elevation of the head end of the table, which acts as counter traction, helps to reduce venous engorgement in the operative field [9]. Complications of Cervical Traction include bleeding from the temporal artery, pressure sore on the skull (hence a downwards vector to rope is to be avoided), sepsis-from the skin to subdural abscess, Worsening neurological status, squint from 6th cranial nerve fallout [10]. Traction should be applied very carefully in patients of Traumatic CVJ cases \& joint distraction has to be avoided in absence of $\mathrm{BI}$, as in patients with traumatic AAD's especially with associated C1/C2 fracture, the ligaments which usually provide strength and stability to C1C2 joints are usually damaged leading to overcorrection of AAD and abnormal posterior translation of $\mathrm{C} 1$ over $\mathrm{C} 2$, which may lead to worsening of symptoms and further compression of the cord [11]. Distraction could either lead to cord stretching or cord compression, which eventually led to intraoperative hypotension. Besides using an Occiput-C2 construct, the other possible method of managing the patient could have been the insertion of transarticular screws.

\section{Conclusion}

Distraction (skull traction as well as direct joint distraction) should be used very cautiously in patients with traumatic AAD as this can result in brain stem/ cervical cord traction. 


\section{References}

1. Meyer C, Eysel P, Stein G (2019) Traumatic Atlantoaxial and fracture related dislocation. BioMed Research International.

2. Goel Atul, (2018) Operative Technique for Goel's Lateral Mass Plate (or Rod) and Screw (Monoaxial or Polyaxial) Fixation. Principles of Neurological Surgery (Fourth Edition).

3. Kataria R. KV Pawan, VD Sinha (2018) Increasing the safety of surgical treatment for complex Cranio-vertebral anomalies using customized 3D printed models. J Clin Neurosci 48: 203-208.

4. Joaquim AF, Tedeschi H, Chandra PS (2018) Controversies in the surgical management of congenital craniocervical junction disorders - a critical review. Neurol India 66(4): 1003-1015.

5. Wang HJ, Alan HD, Mark AP, Craig PE (2014) Cervical Traction for the Treatment of Spinal Injury and Deformity. JBJS REVIEWS 2(5): e4.

6. Shetty A, Kumar A, Chacko A, Guthe S, Kini RA (2013) Reduction techniques in the management of atlantoaxial subluxation. Indian J Orthop 47(4): 333-339.
7. Chandra PS, Goyal N, Chauhan A, Abuzer A, Bhawani SS, et al. (2014) The severity of basilar invagination and atlantoaxial dislocation correlates with sagittal joint inclination, coronal joint inclination, and craniocervical tilt: a description of new indexes for the craniovertebral junction. Neurosurgery 10(4): 621-630.

8. Chandra PS, Prabhu M, Goyal N, Ajay G, Avnish C, et al. (2015) Distraction, compression, extension, and reduction combined with joint remodeling and extra-articular distraction: description of 2 new modifications for its application in basilar invagination and atlantoaxial dislocation: prospective study in 79 cases. Neurosurgery 77(1): 67-80.

9. Saleh H, Yohe N, Razi A, Saleh A (2018) Efficacy and complications of the use of Gardner-Wells Tongs: a systematic review. J Spine Surg 4(1): 123-129.

10. Cervical Tracton. Department of Orthopaedic Surgery - University Stellenbosch, South Africa.

11. Chandra PS, Kumar A, Chauhan A, Abuzar A, Nalin KM, et al. (2013) Distraction, compression, and extension reduction of basilar invagination and atlantoaxial dislocation: a novel pilot technique. Neurosurgery 72(6): 1040-53.

\section{Your next submission with Juniper Publishers will reach you the below assets}

- Quality Editorial service

- Swift Peer Review

- Reprints availability

- E-prints Service

- Manuscript Podcast for convenient understanding

- Global attainment for your research

- Manuscript accessibility in different formats

( Pdf, E-pub, Full Text, Audio)

- Unceasing customer service

Track the below URL for one-step submission https://juniperpublishers.com/online-submission.php 